\title{
A Utilização do Genograma como Instrumento de Coleta de Dados na Pesquisa Qualitativa
}

\author{
Genogram Use as a Collect Tool in Qualitative Research
}

\author{
Naiane Carvalho Wendt ${ }^{*} \&$ Maria Aparecida Crepaldi** \\ Universidade Federal de Santa Catarina
}

\begin{abstract}
Resumo
O Genograma é uma representação gráfica da família e tem sido utilizado em diversos contextos. Este artigo visa destacar a relevância da utilização do genograma na pesquisa qualitativa e propor um procedimento de aplicação e análise do mesmo. As informações reunidas pelo genograma podem incluir aspectos genéticos, médicos, sociais, comportamentais, relacionais e culturais, que denotam a estrutura e configuração da família dando indícios de seu funcionamento e dinâmica. Propõe-se que os questionamentos, comentários e verbalizações realizados pelo pesquisador durante a aplicação do instrumento sejam classificados de acordo com o sistema de categorias pré-determinado, e que os dados obtidos sejam submetidos às análises gráfica, clínica e do discurso, com posterior encaminhamento para cálculo de acordo entre juízes.

Palavras- chave: Genograma; família; pesquisa qualitativa.
\end{abstract}

\begin{abstract}
The genogram is a graphical representation of a family and has been used in several contexts. This paper aims to highlight the genogram use relevance in qualitative research and to propose an application and analysis procedure. The information gathered by the genogram may include genetics, medical, social, behavioral, relational and cultural aspects that denote the family structure and its configuration giving indicia of its functioning and dynamics. It is proposed that the inquiries, comments and verbalizations held by the researcher during the application of the tool are classified, according to the pre-determined categories system and that the data obtained are submitted to graphical, clinical and discourse analysis for later calculus of judges' agreement.

Keywords: Genogram; family; qualitative research.
\end{abstract}

O Genograma Familiar é uma representação gráfica que mostra o desenho ou mapa da família. Também chamado de Genetograma trata-se de um instrumento amplamente utilizado na Terapia Familiar (McDaniel, Hepworth \& Doherty, 1994), na formação de terapeutas familiares (Marchetti-Mercer \& Cleaver, 2000), na atenção primária à saúde (Greenwald, Grant, Kamps \& Haas-Cunningham, 1998; Rocha, Nascimento \& Lima, 2002) e, recentemente, sua aplicação tem sido difundida em pesquisas sobre família (Amazonas, Damasceno, Terto \& Silva, 2003; Castoldi, 2002; Piszezman, 1996; Souza, 2003).

$\mathrm{Na}$ terapia e no aconselhamento familiar, o Genograma é utilizado como um instrumento para engajar a família, destravar o sistema, rever dificuldades familiares, verificar a composição familiar, clarificar os padrões relacionais familiares e identificar a família extensa. Freqüentemente, sua confecção identifica a razão pela qual a família procura a terapia, ou seja, clarifica a demanda existente por trás

* Endereço para correspondência: Familiare - Instituto Sistêmico, Rua Acadêmico Reinaldo Consoni, 85, Córrego Grande, Florianópolis, SC, 88037-416. Tel.: (48) 32334635. E-mail: naiwendt@pop.com.br

** Endereço para correspondência: Universidade Federal de Santa Catarina, Centro de Filosofia e Ciências Humanas, Departamento de Psicologia, Campus Universitário Trindade, Florianópolis, SC, 88040-970. Tel.: (48) 3319283. da queixa explicitada pela família (McGoldrick \& Gerson, 1985/2005; Rotter \& Bush, 2000).

Profissionais que estejam realizando a formação em terapia familiar comumente confeccionam o Genograma de suas famílias de origem, com o intuito de averiguar a composição e dinâmica familiar, elucidando seus padrões, regras, valores, crenças e mitos e sua influência na prática profissional (Hardy \& Laszloffy, 1995; Marchetti-Mercer \& Cleaver, 2000). Este empreendimento costuma fazer parte do trabalho realizado no estudo do self do terapeuta, ou seja, a partir da investigação da estrutura e dinâmica da família de origem, examinam-se quais possíveis dificuldades e facilidades o terapeuta de família teria no desempenho da função terapêutica.

A aplicação do Genograma em saúde da família é extensa. Pode ser utilizado como instrumento importante na caracterização e cadastramento dos grupos familiares na Estratégia de Saúde de Família (ESF), com vistas ao trabalho de promoção à saúde da comunidade e prevenção de agra$\operatorname{vos}^{1}$. Além disso, permite uma visualização do processo de adoecer e das principais enfermidades que acometem os

${ }^{1}$ Considera-se promoção à saúde como "o fortalecimento da capacidade individual e coletiva para lidar com a multiplicidade dos condicionantes de saúde" (p. 47), e a prevenção como o controle de doenças e a redução de riscos (Czeresnia, 2003). 
membros familiares, facilitando o plano terapêutico e permitindo à família uma melhor compreensão sobre o desenvolvimento de suas doenças (Asen \& Tomson, 1997; Filizola, Dupas, Ferreira \& Pavarini, 2004).

Atualmente, o Genograma tem sido difundido como um instrumento científico para coleta de dados, especificamente em pesquisas qualitativas com famílias. Sua utilização tem se mostrado adequada para a pesquisa com famílias em diferentes fases de transição, em processos psicoterapêuticos, em famílias de crianças acometidas por doenças crônicas, famílias de idosos, com transtorno mental, famílias de adultos com câncer, entre outras (Filizola et al., 2004; Nieweglowski, 2004; Wendt, 2006).

De acordo com Burd e Baptista (2004), apenas na década de 80 foi padronizado por um comitê e apresentado por McGoldrick e Gerson (1985/2005) o formato dos genogramas, que até então eram realizados de várias formas, com símbolos diferentes e maneiras próprias de traçar as configurações familiares, o que gerava confusão e impossibilitava a leitura do instrumento por outros profissionais. Sendo assim, este artigo visa destacar a relevância da utilização do Genograma na pesquisa qualitativa e propor um procedimento de aplicação e análise do mesmo.

\section{A Pesquisa com Famílias}

O trabalho de pesquisa com famílias torna-se bastante complexo, sobretudo quando se quer avançar em relação aos dados sócio-demográficos, numéricos, que, sem dúvida, são fundamentais, mas que por si só não dão conta de estudar a complexidade deste grupo social. Considerar o grupo familiar como uma entidade única, com funções específicas e definidas é bastante perigoso tendo em vista a diversidade de modelos familiares existentes no Brasil, além de sua multiplicidade de padrões interativos e comportamentais e dos sistemas simbólicos que abarca. Segundo Bowen (1979/1991) a família é "uma combinação de sistemas emocionais e relacionais. O termo 'emocional' se refere à força que motiva o sistema e 'relacional' ao modo como se expressa. Este último compreende a comunicação, a interação e outras modalidades de relação" (p. 33).

Assim sendo, a pesquisa qualitativa destaca-se por encerrar uma preocupação em estudar as seqüências específicas dos comportamentos interpessoais, nas quais as ações de cada pessoa são visualizadas em uma seqüência interativa que depende das ações dos demais parceiros de interação, ou seja, inclui aspectos complexos de interdependência nas relações familiares, sejam eles emocionais, relacionais, e comunicacionais. Estudando pequenas amostras, os estudos qualitativos privilegiam as regularidades, mas se preocupam com as singularidades nas análises de cada grupo familiar em especial.

$\mathrm{Na}$ pesquisa com famílias é importante não perder de vista a complexidade das relações que este grupo social encerra. Seja qual for a configuração do mesmo deve-se levar em conta a maior quantidade de detalhes que se possa abarcar. Então, o mapeamento das relações, baseandose na máxima de que o triângulo é a unidade mínima de observação é condição essencial para a consecução do estudo da família.

Segundo a teoria sistêmica, representada aqui por Andolfi, Angelo, Menghi e Nicolo-Corigliano (1984), em uma relação dual (casal, mãe-filho, pai-filho) não é possível haver diferenciação se nenhuma das duas partes envolvidas estabelecer relações com um terceiro. Cada componente da família, por sua vez, é parte de uma rede de relações com suas famílias de origem. O termo diferenciação refere-se ao processo de auto-expressão do sujeito, que por sua vez, é membro de um grupo familiar e dele deve diferenciar-se progressivamente para atingir sua autonomia individual (Andolfi et al.).

Para Andolfi et al. (1984), a relação triangular é a unidade mínima que constitui uma ligação estrutural que ajuda a determinar o processo diferenciação/indiferenciação individual. As particularidades que cada família experimenta na formação e destruição de seus triângulos de relação influenciam a transformação de sua estrutura e dinâmica. Portanto, pesquisá-la requer uma análise minuciosa dos triângulos e suas relações recíprocas. Para isto, o Genograma é um instrumento visual importante porque pode servir ao mapeamento desta rede de interações (McGoldrick \& Gerson, 1985/2005).

O Genograma pode ser considerado como um instrumento que auxilia a família a expressar-se, e que vem somar-se à gama de instrumentos de coleta de dados, como os relatos orais para estudos de caso, histórias de vida e entrevistas reflexivas que, como refere Szymanski (2004), permitem a ampla expressão dos participantes.

\section{Genograma Familiar}

O uso do Genograma no campo da terapia familiar é geralmente associado à teoria dos sistemas familiares de Bowen (1979/1991). No início de seu trabalho com famílias, Bowen propôs a utilização de um diagrama familiar, o qual auxiliaria a coletar e organizar importantes dados sobre o sistema familiar multigeracional, e foi renomeado em 1972 por Guerin, como Genograma Familiar (Nichols \& Schwartz, 1998). O Genograma representa o mapeamento gráfico da "história e do padrão familiar, mostrando a estrutura básica, a demografia, o funcionamento e os relacionamentos da família", configurando-se como um gráfico sumário dos dados coletados (McGoldrick \& Gerson, 1995, p. 145). O Genograma explicita a estrutura familiar ao longo de várias gerações e das etapas do ciclo de vida familiar, além dos movimentos emocionais a ele associados.

De acordo com Nichols e Schwartz (1998), a principal função do Genograma é organizar os dados referentes à família durante a fase de avaliação e acompanhar os processos de relacionamento e de triângulos relacionais no decorrer da terapia. O modo como o Genograma é feito, dispõe as informações da família graficamente de forma a oferecer uma visão compreensiva dos complexos padrões familiares. Ao mesmo tempo, possibilita a criação de uma série de hipóteses sobre como o problema clínico da fa- 
mília pode conectar-se ao contexto, bem como a evolução de ambos, problema e contexto, ao longo do tempo (McGoldrick \& Gerson, 1995).

Os Genogramas são baseados na suposição teórica de que o funcionamento dos membros familiares em diferentes níveis, físico, social e emocional, é interdependente, e quando uma parte do sistema familiar muda, todo o resto é afetado (Marchetti-Mercer \& Cleaver, 2000). Autores como Carter e McGoldrick (1995), salientam que certos padrões familiares, em uma mesma família, são recorrentes e, por essa razão, é possível fazer determinadas predições sobre os processos futuros que a família vivenciará baseando-se na utilização do Genograma. De acordo com Bowen (1979/ 1991), deste modo, passado e presente são examinados para se obter possíveis informações sobre o futuro.

Através dos Genogramas é possível acessar os principais mitos e crenças que norteiam a vida da família. Tais mitos tendem a ser transmitidos ao longo das gerações e podem guiar a formação e ruptura dos relacionamentos (Asen \& Tomson, 1997).

As informações reunidas através do Genograma podem incluir aspectos genéticos, médicos, sociais, comportamentais e culturais da família, sendo evidenciados os seguintes dados: (a) os nomes e idades de todos os membros da família; (b) datas exatas de nascimentos, casamentos, separações, divórcios, mortes, abortos e outros acontecimentos significativos; (c) indicações datadas das atividades, ocupações, doenças, lugares de residência e mudanças no desenvolvimento vital; e (d) as relações entre os membros da família.

Tais dados denotam a estrutura da família e podem se configurar como indícios do funcionamento e dinâmica das mesmas.

\section{Estrutura e Dinâmica Familiar}

De acordo com Kreppner e Von Eye (1989), a formação dos subsistemas, a definição das fronteiras entre eles, e as relações entre os elementos de um sistema são abstrações que auxiliam a análise do complexo fenômeno do desenvolvimento familiar e das mudanças nos comportamentos dos membros familiares ao longo do ciclo vital. Essas abstrações referem-se à estrutura e à dinâmica das famílias que, por sua vez, caracterizam as configurações familiares.

Cerveny e Berthoud $(1997,2002)$ consideram como componentes da estrutura familiar as características objetivas que permitem dar configuração ao grupo familiar, tais como o número de componentes, sexo, idade, religião, moradia, nível econômico, profissão, escolaridade, tipo de casamento, tempo de casamento, quem trabalha, cor, raça, background étnico e cultural.

As características subjetivas referentes à maneira como os membros familiares se relacionam conferem indícios da dinâmica da família. Considera-se como dinâmica familiar a forma como os membros da família se relacionam, como estabelecem e mantêm vínculos, como lidam com problemas e conflitos, os rituais que cultivam, a qualidade das regras familiares, a definição de sua hierarquia e o deli- neamento dos papéis assumidos pelos membros da família (Cerveny \& Berthoud, 2002).

Para Minuchin (1982), um dos principais meios de acesso à estrutura e à dinâmica da família é a análise dos subsistemas familiares. Um indivíduo pode participar de diferentes subsistemas nos quais terá diferentes níveis de poder, aprenderá diferentes habilidades e manterá diferentes relações complementares. Cada subsistema familiar realiza e formula funções e demandas específicas de cada um de seus membros, sendo que o desenvolvimento das competências pessoais adquiridas em cada um desses subsistemas depende do grau de autonomia atingido pelos mesmos. De acordo com Andolfi et al. (1984), a capacidade de mudar, participar, deslocar-se, separar-se e pertencer a diversos subsistemas permite aos indivíduos exercerem, junto à família, funções únicas, trocar e adquirir funções e, desse modo, expressar aspectos mais diferenciados de si mesmos.

Os subsistemas, por sua vez, são separados por fronteiras e regras cujas funções são estabelecer limites próprios e regular as trocas estabelecidas entre eles, o que permite a manutenção dos mesmos. Quando os limites são suficientemente bem definidos para permitir contato entre os membros de diferentes subsistemas e o cumprimento de suas funções, sem a interferência indevida dos outros, considera-se que as fronteiras sejam nítidas. Quando não existem limites entre os subsistemas, considera-se que as fronteiras sejam difusas, o que promove um padrão de funcionamento emaranhado na família. Quando existem limites excessivos, as fronteiras podem se tornar rígidas, promovendo um padrão de desligamento com o qual os membros dos subsistemas têm pouco ou nenhum contato (Minuchin, 1982).

Ainda conforme Minuchin (1982), nos subsistemas ou famílias emaranhadas, ou seja, nas famílias com fronteiras difusas, o comportamento e os sentimentos de um membro afetam imediatamente os demais, o que pode produzir um aumento exacerbado do sentimento de pertencimento ao grupo. Esse sentimento, por sua vez, implica em uma significativa renúncia à exploração da autonomia e domínio de problemas e pode se transformar em um importante fator de desenvolvimento de sintomas e inibição de habilidades cognitivo-afetivas e sociais.

Nos subsistemas ou famílias desligadas, cujas fronteiras são rígidas, pode haver um senso distorcido de independência e carência de sentimentos de lealdade, pertencimento e interdependência, sendo necessários níveis elevados de stress para acionar o apoio dos demais membros.

A função das fronteiras é proteger a diferenciação do sistema e de seus membros, permitindo, ao mesmo tempo, a aquisição de competências interpessoais dentro dos subsistemas e em contatos com o exterior (Miermont, 1994).

Com a chegada dos filhos, a família expande as relações existentes ou muda a estrutura interna, possibilitando a formação de novos subsistemas por meio de relacionamentos diádicos e triádicos no interior do sistema familiar (Kreppner \& Von Eye, 1989). Para estes autores, o número de relacionamentos que podem ser observados é o primei- 
ro aspecto da estrutura familiar a ser considerado e o aumento ou diminuição nas possibilidades de relacionamentos caracteriza-se como um ponto importante na descrição das características estruturais do sistema.

A recorrência de algumas formas de relacionamento entre determinados membros da família origina padrões transacionais, ou seja, padrões de relacionamentos cristalizados no sistema familiar.

Com base na experiência clínica das autoras e na literatura foram definidos os seguintes padrões transacionais: relacionamento harmônico; relacionamento muito estreito ou superenvolvimento; relacionamento fundido e conflitual; aliança; relacionamento conflituoso; relacionamento vulnerável; relacionamento distante; rompimento; triangulação; e coalizão.

A literatura contribuiu com os conceitos de: emaranhamento e rigidez de fronteiras (Minuchin, 1985); rompimento, superenvolvimento, fusão, diferenciação e triangulação (Bowen, 1979/1991); lealdades invisíveis (BoszormenyiNagy, 2003); e comunicação disfuncional, definida por Watzlawick, Beavin e Jackson (1973) como a comunicação permeada de paradoxos, desqualificações e desconfirmações $^{2}$ do outro, simetria e complementaridade ${ }^{3}$.

A seguir apresentam-se as definições de cada um dos padrões transacionais:

O relacionamento harmônico define-se como a experiência emocional de união entre dois ou mais membros familiares que nutrem sentimentos positivos um para com o outro e que possuem interesses, atitudes ou valores recíprocos. Inclui diferenciação dos membros entre si e com suas famílias de origem.

O relacionamento muito estreito ou superenvolvimento caracteriza os relacionamentos nos quais há fusão e dependência emocional entre os membros familiares, ou seja, caracteriza relacionamentos nos quais não há diferenciação entre os membros.

O relacionamento fundido e conflitual caracteriza os relacionamentos nos quais existe estreita dependência emocional e presença constante de conflitos entre os membros familiares, não havendo diferenciação entre os mesmos.

Embora o termo aliança suscite interações positivas, trata-se de uma ligação baseada nas lealdades invisíveis que interferem, também, no processo de diferenciação, porém em menor grau que o superenvolvimento.

O relacionamento conflituoso caracteriza-se pelas relações nas quais há constantes atritos que geram muita ansiedade e desavenças no meio familiar traduzidos por dificul-

\footnotetext{
${ }^{2}$ A desqualificação diz respeito à invalidação da comunicação por meio de contradições, incoerências, mudanças bruscas de assunto, frases incompletas, interpretações errôneas, entre outros, ao passo que a desconfirmação nega a realidade e a existência do outro ignorando-o completamente (Watzlawick, Beavin \& Jackson, 1973).

${ }^{3} \mathrm{Na}$ simetria, os parceiros tendem a engajarem-se em escaladas simétricas ou cismas, nas quais um reflete o comportamento do outro ampliando a fraqueza, competição e agressividade de ambos; na complementaridade, o comportamento de um casal complementa o do outro, aumentando a imperatividade de um e a submissão do outro (Watzlawick et al., 1973)
}

dades de comunicação, tais como desqualificações e desconfirmações do outro, podendo evoluir para padrões de comunicação simétricos capazes de gerar violência física;

O relacionamento vulnerável caracteriza os relacionamentos nos quais não há conflito explícito, mas que, entretanto, apresentam risco de haver conflitos em condições adversas ou fases de transição;

$\mathrm{O}$ relacionamento distante caracteriza a forma de relacionamento encontrada principalmente nas famílias desligadas, com fronteiras rígidas. O relacionamento entre os membros caracteriza-se por pouco contato, principalmente de ordem emocional;

O rompimento caracteriza os relacionamentos nos quais a ligação emocional entre os membros é mantida, apesar de não haver contato entre os mesmos.

A triangulação é a configuração emocional de três pessoas, na qual a pessoa "triangulada" cumpre uma função periférica de regulação da tensão existente entre outras duas e, "na ausência de conflito explícito, encontra-se em um estado de insegurança e mesmo de sofrimento emocional. Em caso de conflito, o embaraço, ou o sofrimento, desviase e é transferido para os membros da díade, enquanto o terceiro vê-se aliviado" (Miermont, 1994, p. 571).

A coalizão de acordo com Miermont (1994, p. 144), "consiste na aliança de duas pessoas contra uma terceira" e também se caracteriza como uma propriedade específica das tríades.

Apesar de recorrentes, os padrões transacionais podem ser modificados ao longo do tempo, o que ocorre, principalmente, durante as fases de transição pelas quais passa a família. A mudança dos padrões transacionais permite a continuidade da família e, reciprocamente, a diferenciação de seus membros.

\section{Utilização do Genograma em Pesquisa Qualitativa}

Filizola et al. (2004) descrevem o desenvolvimento do Genograma como um procedimento complexo no qual a entrevista é uma parte significativa e a interação que ocorre entre o profissional e a família pode ser entendida como um processo envolvendo interação social, recuperação de memórias e desenvolvimento próprio.

Para ilustrar o processo de aplicação do Genograma como instrumento de coleta de dados, utilizamos como exemplo uma pesquisa com famílias durante a transição para a parentalidade (Wendt, 2006). Nesta pesquisa, os dados do Genograma foram coletados a partir de entrevistas semiestruturadas com as famílias, por meio da quais se suscitaram verbalizações representadas graficamente com símbolos e siglas adotados conforme proposto por McGoldrick e Gerson (1995) e Minuchin (1982) em anexo. Geralmente a confecção do Genograma iniciava-se a partir da seguinte instrução:

Uma das partes da nossa pesquisa é a construção de um mapa familiar, onde desenhamos todas as pessoas que fazem parte da família, as relações entre elas e os acontecimentos importantes. Nós gostaríamos que vocês nos ajudassem a desenhar o mapa da família de vocês, incluindo as famílias de origem do pai e da mãe: seus 
pais, irmãos e, inclusive, aquelas pessoas que não são parentes, mas que estão muito próximas e são muito íntimas de vocês. A construção desse mapa dura aproximadamente 1 hora e pode ser interrompida por nós ou por vocês se houver necessidade. Podemos começar agora?

Para começarmos a fazer o desenho da família de vocês, nós gostaríamos que vocês contassem quem são as pessoas que fazem parte da família, as idades, as ocupações, as coisas boas e ruins que marcaram as famílias (essa e as famílias de origem dos pais) . . . Precisamos marcar no desenho as pessoas que já faleceram ou que apresentam alguma condição especial... Vocês podem começar por onde quiserem... Quem quer começar? Nós representamos os homens por quadrados e as mulheres por círculos ... .

A entrevista teve por objetivo focalizar a fase da transição para a parentalidade e, quando determinados tópicos, necessários para atingir os objetivos da pesquisa não eram explícitos, a pesquisadora retomava-os. Salienta-se que, em momento algum, se interferiu intencionalmente nas relações familiares com intervenções que se aproximassem daquelas que são utilizadas em um atendimento clínico e que, portanto, encerram intervenção e manejo psicoterapêuticos.

Tendo em vista que algumas pessoas apresentam dificuldade para conversar sobre padrões e acontecimentos familiares, pois estes podem causar sofrimento, a pesquisadora baseou-se em sua experiência clínica com famílias e no proposto por Asen e Tomson (1997) que enfatizam a necessidade de alternar os questionamentos, quando necessário, com comentários empáticos, observando-se cuidadosamente os sinais verbais e não-verbais emitidos pelos membros da família para verificar se havia algum indício de incômodo.

Os questionamentos, comentários e verbalizações realizados durante a confecção de Genograma foram adaptados a partir do sistema de categorias desenvolvido por Crepaldi (1989) sobre o significado da comunicação, que se apresenta a seguir:

1. Categorias de incentivo à comunicação: categorias que indicam incentivo ou expectativa em relação à participação do outro: (a) oportunizar verbalização - indicar verbal ou gestualmente a oportunidade e/ou propriedade do momento para que o outro fale; (b) solicitar informação específica - indicar ao outro que faça detalhamento, esclarecimento ou explicação de relato de eventos ou fatos especificados. Pode incluir pedido de opinião; (c) solicitar relato de estado subjetivo - indicar ao outro que fale sobre o que está sentindo ou aspirando; (d) solicitar retomada de assunto - indicar ao outro que volte a falar sobre assunto que fora tratado anteriormente; (e) solicitar mudança de assunto indicar ao outro que passe a falar de outro assunto.

2. Categorias de destaque e clarificação de conteúdos: indicam destaque e clarificação de conteúdos por parte da pesquisadora: (a) repetir - dizer exatamente o que foi dito anteriormente pelo informante; (b) tradu- zir - parafrasear o informante com palavras mais simples, tornando a verbalização mais clara.

3. Categoria de apoio: indica manifestação de apoio. Apoiar - indicar ao outro que está entendendo as condições, as situações e os sentimentos relatados. Geralmente é antecedido de verbalizações sobre o enfrentamento de dificuldades diante da transição e situações de vida diária.

Ao final da entrevista, a pesquisadora oportunizava à família acrescentar mais informações que julgassem necessárias ou quisessem compartilhar. Ressalta-se que se realizou esta entrevista apenas na segunda visita, após ter sido estabelecido um vínculo com os participantes do estudo, o que, por sua vez, facilitou a obtenção de informações de cunho mais íntimo.

\section{Proposta de Análise do Genograma}

Embora a literatura disponha de uma metodologia quantitativa para análise do Genograma, através da pontuação e cotação dos valores para cada característica apresentada pelas famílias (Greenwald et al., 1998), na pesquisa de Wendt (2006) a autora optou pela análise qualitativa dos dados colhidos durante a entrevista semi-estruturada e a confecção do Genograma. Para tanto, estes foram submetidos às análises gráfica e clínica, cujas definições dos padrões relacionais e símbolos foram, a priori, ancoradas na literatura (McGoldrick \& Gerson, 1995; Minuchin, 1982) e na experiência clínica da pesquisadora e foram redefinidos, posteriormente, a partir do dado coletado.

Após as análises clínica e gráfica e redefinição de cada categoria representativa dos padrões relacionais e seus símbolos, apresentou-se a dois juízes, terapeutas de família experientes, a transcrição de três entrevistas. Cada uma delas foi acompanhada das respectivas estruturas familiares, das definições dos símbolos e dos padrões de relacionamento. À eles foi solicitado que obedecessem às seguintes instruções: (a) ler as definições das relações familiares; (b) ler cada entrevista; (c) classificar as relações familiares segundo as definições utilizando os respectivos símbolos e, se julgar necessário, escrever à parte comentários e observações.

Posteriormente, compararam-se os símbolos e padrões relacionais atribuídos pelos juízes a cada família e discutiu-se sobre a necessidade de inclusão de novos símbolos e definições de padrões relacionais que melhor explicitassem as relações. A partir da inserção de novos símbolos e definições, solicitou-se, aos juízes, uma segunda análise. A partir desta, efetuou-se o cálculo de acordo entre juízes, que foi de $88 \%, 100 \%$ e $90 \%$. É importante lembrar que este cálculo derivou-se daquele que é realizado na metodologia observacional (Danna \& Matos, 1982).

Após a finalização das análises gráfica e clínica, realizou-se a análise do discurso das entrevistas, na qual se inseriram os padrões relacionais das análises, gráfica e clínica como elementos das subcategorias. Utilizou-se a análise do discurso, baseada em Brandão (1991) e Maingueneau (1989) devido à possibilidade de englobar à mesma as manifesta- 
ções verbais e não-verbais de todos os informantes. Exemplos de manifestações descritas pelos autores e observadas durante as entrevistas são: ironias, negações, paráfrases, entonações, expressões faciais, gestos, silêncios e interações entre os cônjuges, pais-avós e pais-tios. O conteúdo analisado foi composto pela entrevista como um todo.

De acordo com os autores acima citados, a análise do discurso é utilizada sempre que se pretende captar um sentido oculto no discurso. Isto apenas é possível a partir da análise das minúcias do mesmo. Os resultados deste trabalho podem ser encontrados em Wendt (2006).

\section{Considerações Finais}

O Genograma demonstrou-se adequado para utilização em estudos que englobam a dinâmica e estrutura das famílias. Ressalta-se que, diferente de outras entrevistas, a entrevista de confecção do Genograma não deve seguir uma ordem previamente estabelecida, mas a ordem proposta por cada família. Dessa forma, evitam-se mudanças bruscas de assunto e proporciona-se uma escuta empática aos entrevistados.

A necessidade de realizar uma escuta empática e acolhimento dos entrevistados exige envolvimento recíproco entre pesquisador-pesquisados e, principalmente, que este instrumento seja utilizado por terapeutas familiares ou profissionais com formação para o trabalho com famílias ou terapia familiar, tendo em vista a mobilização ocasionada nos informantes durante a confecção do Genograma. Além disso, é necessário que durante toda a entrevista o pesquisador não apenas preste atenção contínua às manifestações verbais e não-verbais dos entrevistados, como nas suas próprias, pois suas reações podem facilitar, intimidar ou mesmo inibir o relato da família, principalmente em temas relacionados a intimidade familiar.

Elkaïn (1990) desenvolveu o conceito de ressonância justamente para compreender os conteúdos que surgem entre terapeuta e paciente, de modo que os mesmos possam ser trabalhados a favor de ambos. Refere-se ao conhecimento que emerge da vivência pessoal, pois é o próprio observador que constrói a sua percepção do real.

O conceito de ressonância permite e autoriza que os dois sistemas paciente/terapeuta, ou no caso da pesquisa, entrevistador/entrevistado, interajam a partir da sua condição humana e, desse modo, legitima a experiência da intersubjetividade num contexto relacional:

a ressonância não é 'um fato objetivo', não se trata de uma verdade velada que devamos fazer surgir através de um ponto em comum dos diversos sistemas. Ela nasce na construção mútua do real que se opera entre aquele que nomeia e o contexto no qual ele se descobre nomeando. (Elkaïn, 1990, p. 171).

Por este motivo, sugere-se que a confecção do Genograma, ou seja, o desenho da estrutura familiar e a visualização dos símbolos, que indicam os padrões relacionais, seja realizada junto com os informantes. Assim, eles podem corrigir possíveis mal-entendidos e incrementar informações.
Na pesquisa mencionada (Wendt, 2006), contou-se com a presença de ambos os cônjuges durante a confecção do Genograma somente em duas famílias. Nas oito demais apenas a mãe foi informante com a participação eventual de tias, de avós ou de empregada. Nestes casos, a confecção, bem como a análise dos dados, foi realizada apenas sob a ótica de um dos cônjuges. Nos casos em que o casal foi informante, foi possível constatar as divergências ou a concordância de ambos na visualização da dinâmica familiar.

Propõe-se que, em estudos posteriores que visem averiguar o padrão relacional das famílias, principalmente as relações conjugais, a confecção do Genograma seja realizada com ambos os cônjuges ou, então, que o cônjuge nãoparticipante seja solicitado a visualizar o Genograma pronto e expressar sua concordância ou não com as informações demonstradas no mesmo.

Ainda com relação ao Genograma, evidencia-se a necessidade de construí-lo para as diferentes fases vivenciadas pela família a fim de explicitar as modificações familiares ao longo do tempo. No entanto, como esse mapa familiar não abarca a dimensão temporal, sugere-se a confecção de dois ou mais Genogramas para a explicitação das mudanças.

\section{Referências}

Andolfi, M., Angelo, C., Menghi, P., \& Nicolo-Corigliano, A. M. (1984). Por trás da máscara familiar - Um novo enfoque em terapia da família (3. ed., M. C. R. Goulart, Trad.) Porto Alegre, RS: Artes Médicas.

Amazonas, M. C. L. A., Damasceno, P. R., Terto, L. M. S., \& Silva, R. R. (2003). Arranjos familiares de crianças das camadas populares. Psicologia em Estudo, Maringá, 8, 11-20.

Asen, K. E., \& Tomson, P. (1997). La familia dentro de nosotros: genogramas. In K. E. Asen \& P. Tomson (Eds.), Intervención familiar - guía práctica para los profisionales de la salud. Barcelona, España: Paidós.

Boszormenyi-Nagy, I., \& Spark, G. M. (2003). Lealtades invisibles. Madrid, España: Amorrortu.

Bowen, M. (1991). De la familia ao individuo. Barcelona, España: Paidós. (Original publicado em 1979)

Brandão, H. H. N. (1991). Introdução à análise do discurso. Campinas, SP: Editora da Universidade de Campinas.

Burd, M., \& Baptista, C. (2004). Anamnese da família: Genograma e linha do tempo. In J. Mello Filho \& M. Burd (Eds.), Família e doença (pp. 93-110). São Paulo, SP: Casa do Psicólogo.

Carter, B., \& McGoldrick, M. (1995). As mudanças no ciclo de vida familiar - Uma estrutura para a terapia familiar (2. ed., M. A. V. Veronese, Trad.) Porto Alegre, RS: Artes Médicas.

Castoldi, L. (2002). A construção da paternidade desde a gestação até o primeiro ano do bebê. Tese de Doutorado nãopublicada, Programa de Pós-Graduação em Psicologia do Desenvolvimento, Universidade Federal do Rio Grande do Sul, Porto Alegre, RS.

Czeresnia, D. (2003). O conceito e saúde e a diferença entre prevenção e promoção. In D. Czeresnia \& C. M. Freitas (Eds.), Promoção da saúde: Conceitos, reflexões, tendências. Rio de Janeiro, RJ: Fundação Oswaldo Cruz.

Cerveny, C. M. O., \& Berthoud, C. M. (1997). Família e ciclo vital: Nossa realidade em pesquisa. São Paulo, SP: Casa do Psicólogo. 
Cerveny, C. M. O., \& Berthoud, C. M. (2002). Visitando a família ao longo do ciclo vital. São Paulo, SP: Casa do Psicólogo. Crepaldi, M. A. (1989). Hospitalização infantil: Estudo das interações famílialequipe hospitalar. Dissertação de Mestrado não-publicada, Programa de Pós-Graduação em Psicologia Clínica, Pontifícia Universidade Católica do Rio de Janeiro, RJ.

Danna, M. F., \& Matos, M. A. (1982). Ensinando observação: Uma introdução. São Paulo, SP: Edicon.

Elkaïn, M. (1990). Se você me ama, não me ame. São Paulo, SP: Papirus.

Filizola, C. L. A., Dupas, G., Ferreira, N. M. L. A., \& Pavarini, S. C. I. (2004). Genograma e Ecomapa: Instrumentos para pesquisa com famílias. In I Conferência Internacional do Brasil de Pesquisa Qualitativa [CD]. Taubaté, SP: Núcleo de Pesquisa da Família.

Greenwald, J. I., Grant, W. D., Kamps C. A., \& HaasCunningham, S. (1998). The genogram scale as a predictor of high utilization in a family practice. Families, Systems \& Health, 16(4), 375-392.

Hardy, K. H., \& Laszloffy, T. A. (1995). The cultural Genogram: Key to training culturally competent family therapists. Journal of Marital and Family Therapy, 21(3), 227-237.

Kreppner, K., \& Von Eye, A. (1989). Family systems and family development: The selection of analytical units. In K. Kreppner \& R. M. Lerner (Eds.), Family systems and life-span development (pp. 247-269). Hillsdale, NJ: Lawrence Erlbaum.

Maingueneau, D. (1989). Novas tendências em análise do discurso (F. Indursky, Trad.). Campinas, SP: Editora da Universidade Estadual de Campinas.

Marchetti-Mercer, M. C., \& Cleaver, G. (2000). Genograms and family sculpting: An aid to cross-cultural understanding in the training of psychology students in South Africa. The Counseling Psychologist, 28(1), 61-80.

McDaniel, S. H., Hepworth, J., \& Doherty, W. (1994). Terapia familiar médica: Um enfoque biopsicossocial às famílias com problemas de saúde (D. Batista, Trad.) Porto Alegre, RS: Artes Médicas.

McGoldrick, M., \& Gerson, R. (1995). Genetogramas e o ciclo de vida familiar (M. A. V. Veronese, Trad.). In B. Carter \& M. McGoldrick, M. (Eds.), As mudanças no ciclo de vida familiar - Uma estrutura para a terapia familiar (2. ed.). Porto Alegre, RS: Artes Médicas.

McGoldrick, M., \& Gerson, R. (2005). Genogramas en la evaluacion familiar (5. ed.). Barcelona, España: Gedisa. (Original publicado em 1985)

Miermont, J. (1994). Dicionário de terapias familiares: Teorias e práticas (C. A. Molina-Loza, Trad.). Porto Alegre, RS: Artes Médicas.

Minuchin, S. (1982). Famílias: Funcionamento e tratamento. Porto Alegre, RS: Artes Médicas.

Minuchin, P. (1985). Families and individual development: Provocations from the field of family therapy. Child Development, 56, 289-302.

Nichols, M. P., \& Schwartz, R. C. (1998). Terapia familiar: Conceitos e métodos. Porto Alegre, RS: Artmed.

Nieweglowski, V. H. (2004). Unidade de terapia intensiva pediátrica: Vozes e vivências da família. Dissertação de Mestrado não-publicada, Programa de Pós-Graduação em Psicologia, Universidade Federal de Santa Catarina, Florianópolis, SC.

Piszezman, M. L. R. M. (1996). Terapia familiar breve: Uma experiência de implantação. Dissertação de Mestrado nãopublicada, Programa de Pós-Graduação em Psicologia Clínica, Pontifícia Universidade Católica de São Paulo, SP.
Rocha, S. M. M., Nascimento, L. C., \& Lima, R. A. G. (2002). Enfermagem Pediátrica e abordagem da família: Subsídios para o ensino de graduação. Revista Latino-americana de enfermagem, 10(5), 709-714.

Rotter, J. C., \& Bush, M. V. (2000). Play and family therapy. The Family Journal: Counseling and Therapy for Couples and Families, 8(2), 172-176.

Szymanski, H. (2004). A pesquisa-intervenção participante com famílias de baixa renda: Um projeto participativo de atenção psicossocial. In C. R. Althoff, I. Elsen \& R. G. Nitschke (Eds.), Pesquisando a família: Olhares contemporâneos (pp. 115-125). Florianópolis, SC: Papa Livro.

Souza, M. T. S. (2003). Resiliência na terapia familiar: Construindo, compartilhando e ressignificando experiências. Tese de Doutorado não-publicada, Programa de Pós-Graduação em Psicologia Clínica, Pontifícia Universidade Católica de São Paulo, SP.

Watzlawick, P., Beavin, J. H., \& Jackson, D. D. (1973). Pragmática da comunicação humana. São Paulo, SP: Cultrix.

Wendt, N. C. (2006). Fatores de risco e de proteção para o desenvolvimento da criança durante a transição para a parentalidade. Dissertação de Mestrado não-publicada, Programa de Pós-Graduação em Psicologia, Universidade Federal de Santa Catarina, Florianópolis, SC. 
ANEXO

\section{Símbolos Genetograma}

(Baseado em McGoldrick \& Gerson, 1995; Minuchin, 1982)

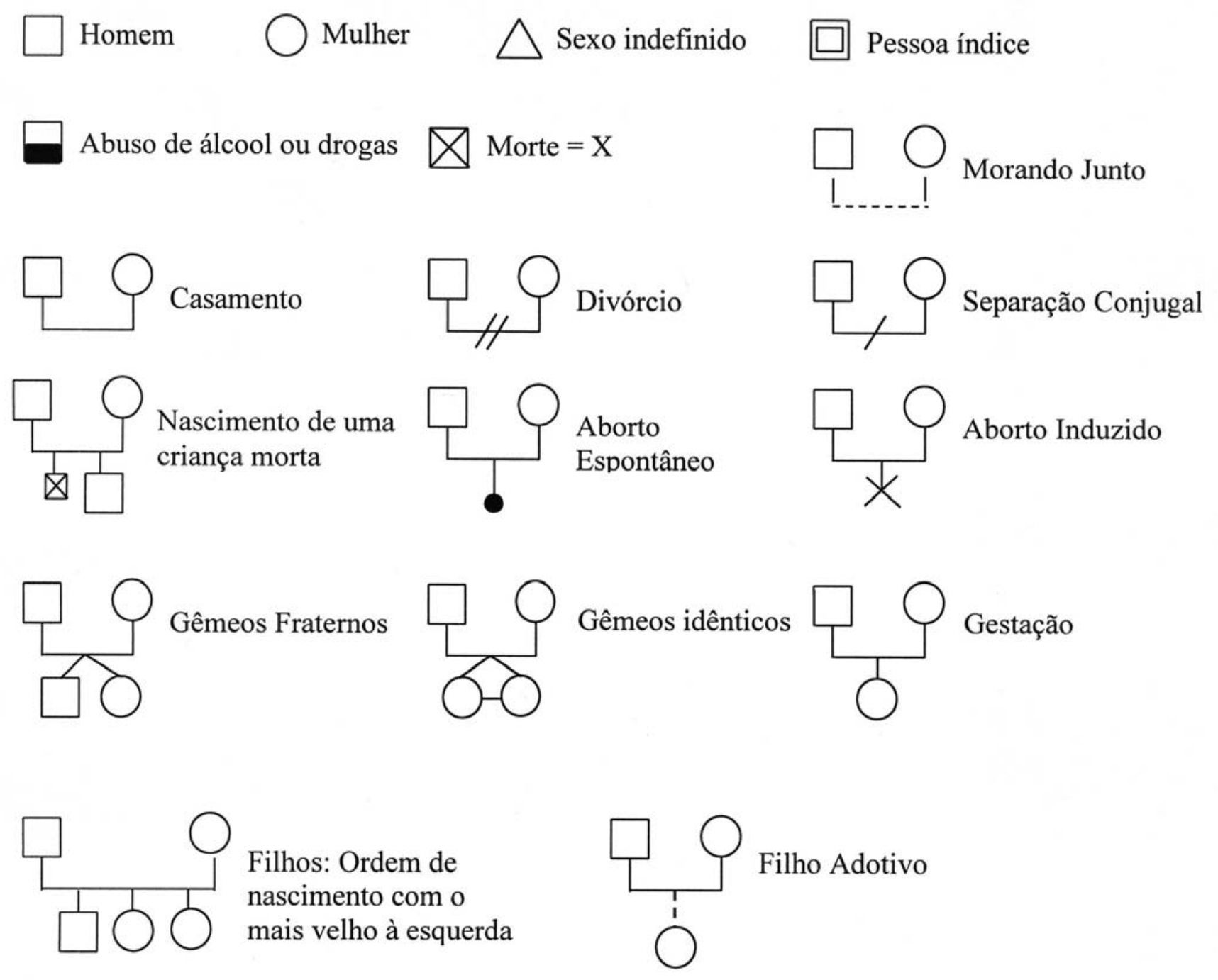

Relacionamentos:

$\square---\bigcirc$ Distante

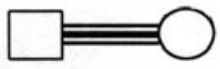

Muito estreito

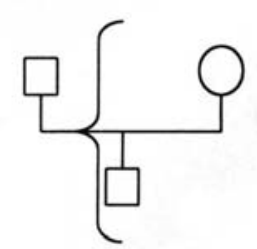

Coalizão $\square \mathrm{m} M$ Conflituoso

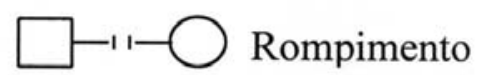

$\square \bigcirc$ Fundido e Conflitual

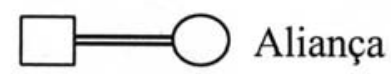

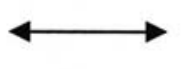

Harmônico

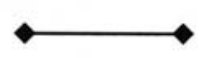

Vulnerável

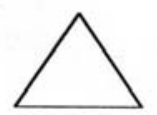

Triangulação 
Outras informações familiares de especial importância também podem ser anotadas (McGoldrick \& Gerson, 1995):

1. Background étnico.

2. Religião ou mudança religiosa.

3. Educação.

4. Ocupação ou desemprego.

5. Serviço Militar.

6. Aposentadoria.

7. Problemas com a lei.

8. Abuso físico ou incesto.

9. Obesidade.

10. Fumo.

11. Data que membros da família deixaram a casa: DC'74. 